\title{
Unconventional Microstructures in Tool Steel Obtained by Semi-Solid Processing and Subsequent Heat Treatment
}

\author{
AIŠMAN David ${ }^{1, a}$, MAŠEK Bohuslav ${ }^{1, ~ b}$, JENíČEK Štěpán ${ }^{1, c}$
}

\author{
${ }^{1}$ University of West Bohemia in Pilsen, Research Centre of Forming Technology - FORTECH, \\ Univerzitní 22, CZ-30614 Pilsen, Czech Republic \\ adaisman@vctt.zcu.cz, ${ }^{\mathrm{b}}$ bohuslav.masek@mb.tu-chemnitz.de, ${ }^{\mathrm{c} j e n i c e k s @ v c t t . z c u . c z ~}$
}

Keywords: semi-solid state, $\mathrm{X} 210 \mathrm{Cr} 12$, metastable austenite, thixoforming, mini-thixoforming

\begin{abstract}
Mechanical properties of all metals depend predominantly on the type and morphology of their microstructure. Microstructure attributes can be altered by various heat treating and thermomechanical treatment procedures. One of the advanced techniques profoundly affecting the microstructure evolution is semi-solid processing. It can produce unconventional microstructures even in conventional steel types. Moreover, subsequent heat treatment can also deliver a wide range of microstructures and correspondingly varied mechanical properties. In the present experimental programme, the $\mathrm{X} 210 \mathrm{Cr} 12$ ledeburitic tool steel was studied. Its initial annealed microstructure consisted of ferritic matrix, chromium carbides and globular cementite particles. The semi-solid processed structure, on the other hand, contained polyhedral austenite grains embedded in carbideaustenite network. The austenite volume fraction exceeded $95 \%$. This microstructure was then altered by subsequent heat treatment or thermomechanical treatment. The experimental programme comprised three stages. At the first stage, the effects of the rate of cooling from the semi-solid region to the ambient temperature on the nature and morphology of the ledeburitic network and the austenitic grain size were explored. The second stage was aimed at the impact of tensile and compressive deformation applied after transition through semi-solid state on the microstructure evolution and, in particular, on grain size. Once suitable processing conditions and parameters were identified, the treatment led to a recrystallized austenitic microstructure with an average grain size of less than $3 \mu \mathrm{m}$. As high volume fractions of austenite were obtained, the third stage involved exploring the effects of thermal exposure. The stability of austenite and the decomposition of austenite into other microstructure constituents were mapped. Metallographic observation revealed a resulting wide range of microstructures from fine pearlite to martensite, depending on the heat treating schedule.
\end{abstract}

\section{Introduction}

Semi-solid processing allows complex-shaped components to be made using a single forming step and unconventional microstructures with altered mechanical properties to be obtained [1]. Unconventional microstructures can also be achieved in steels used ordinarily in practice [2]. The microstructure resulting from semi-solid processing is defined by the heating parameters, such as the heating method, rate and holding time, as well as by the manner of cooling to the ambient temperature [3]. The microstructure can also be altered by deformation applied to the solidified material.

It was shown that heat treating following the above processes can induce other remarkable morphological transformations [4,5]. The austenitic microstructure formed on transition through semi-solid state remains stable up to $400{ }^{\circ} \mathrm{C}$. The metastable austenite only begins to decompose after long-term exposure at $500{ }^{\circ} \mathrm{C}$ [6]. The key aim of the present research was to combine plastic deformation applied after transition through semi-solid state and heat treating. The heat treating was intended to cause austenite decomposition and to modify the ledeburitic network. The combination of semi-solid processing and heat treatment promises to deliver new fine-grained microstructures with uniformly dispersed primary chromium carbides, as well as interesting mechanical properties. 


\section{Experimental}

The experimental programme was divided into three stages (Tab. 2). The common component of all schedules was heating to the semi-solid region, to the temperature of $1265^{\circ} \mathrm{C}$, over 56 seconds and holding for 10 seconds to equalize temperatures in the specimen and homogenize the material. According to JMatPro software calculations, there should be approximately $30 \%$ liquid fraction at $1265^{\circ} \mathrm{C}$ [7]. At the first stage, the impact of the rate of cooling from semi-solid region on the final microstructure was explored (Tab. 2). Three cooling schedules were proposed for this purpose. The first schedule comprised water cooling from the soaking temperature of $1265^{\circ} \mathrm{C}$ to the ambient temperature. The initial cooling rate of $100 \mathrm{~K} / \mathrm{s}$ was kept constant down to approximately $850{ }^{\circ} \mathrm{C}$. The schedule no. 2 involved cooling in air from the soaking temperature down to the ambient temperature at the initial rate of $12 \mathrm{~K} / \mathrm{s}$. The schedule no. 3 comprised controlled cooling at $1 \mathrm{~K} / \mathrm{s}$.

Tab. 1 Chemical composition of experimental material

\begin{tabular}{|l|l|l|l|l|l|l|l|}
\hline Element & $\mathrm{C}$ & $\mathrm{Cr}$ & $\mathrm{Mn}$ & $\mathrm{Si}$ & $\mathrm{Ni}$ & $\mathrm{P}$ & $\mathrm{S}$ \\
\hline Content [\%] & 2.01 & 11.3 & 0.27 & 0.23 & 0.08 & 0.014 & $<0.001$ \\
\hline
\end{tabular}

At the second stage of the experiment, the effects of deformation following the transition through semi-solid state were explored (Tab. 2). The purpose was to support dynamic recrystallization of primary austenite grains by introducing deformation energy and, if relevant, to break up the developing ledeburitic network in order to obtain fine-grained microstructure without any extensive carbide-austenite network.

The thermal-deformation schedule comprised heating to the semi-solid region, i.e. to $1265{ }^{\circ} \mathrm{C}, 10$ second holding, rapid cooling to the forming temperature, forming and, finally, air cooling. A total of three deformation temperatures were used: $1150{ }^{\circ} \mathrm{C}$ (schedule 4), $1050{ }^{\circ} \mathrm{C}$ (schedule 5) and $900{ }^{\circ} \mathrm{C}$ (schedule 6). In all cases, the amount of logarithmic strain was equal: $\varphi=3.13$. The deformation processing comprised one compressive step with a strain of $\varphi=0.7$, immediately followed by three-step tensile-compressive incremental deformation. The deformation was completed in 4 seconds, during which the specimen temperature dropped by approximately $45^{\circ} \mathrm{C}$ in all schedules.

The third stage of the experiment focused on the effects of holding during cooling from the semisolid region and the effects of heat treating upon semi-solid processing (Tab. 2). At the previous stages, the best results in terms of grain refinement and partial disintegration of the network were achieved with the schedule 5. Hence, it became the core of the extended versions employed at the third stage. As the austenite resulting from the transition through semi-solid state remains stable up to approx. $500{ }^{\circ} \mathrm{C}$ and decomposes only above this temperature [8], the temperature for the hold incorporated in the cooling procedure was set at $600{ }^{\circ} \mathrm{C}$. Schedule 7 consisted of heating to the semi-solid region, rapid cooling to the deformation temperature of $1050{ }^{\circ} \mathrm{C}$, deformation, air cooling to $600{ }^{\circ} \mathrm{C}$, holding for 900 seconds and air cooling to the ambient temperature. Its purpose was to test whether the austenite decomposes completely. Schedule 8 was identical to schedule 7 , with the exception of three added steps: reheating to $1000{ }^{\circ} \mathrm{C}$, holding for 10 seconds and quenching in water. In schedule 9, reheating to the austenite region was followed by cooling to $500{ }^{\circ} \mathrm{C}$. Its purpose was to promote precipitation of very fine carbides and remove coarse primary chromium carbides. 
Tab. 2 Parameters of schedules and the resulting properties

\begin{tabular}{|c|c|c|c|c|c|c|c|c|c|}
\hline & & $\begin{array}{l}\text { Cooling } \\
\text { rate }[\mathrm{K} / \mathrm{s}]\end{array}$ & $\begin{array}{c}\text { Strain } \\
\Phi[-]\end{array}$ & $\begin{array}{l}\mathrm{DT}^{*} \\
{\left[{ }^{\circ} \mathrm{C}\right]}\end{array}$ & $\begin{array}{l}\mathrm{TT}^{*} \\
{\left[{ }^{\circ} \mathrm{C}\right]}\end{array}$ & $\begin{array}{c}\text { RHT }^{*} \\
{\left[{ }^{\circ} \mathrm{C}\right]}\end{array}$ & $\begin{array}{c}\mathrm{H}^{*} \\
\text { HV10 }\end{array}$ & $\begin{array}{l}\mathrm{AF}^{*} \\
{[\%]}\end{array}$ & $\begin{array}{c}\mathrm{GS}^{*} \\
{[\mu \mathrm{m}]}\end{array}$ \\
\hline \multirow{3}{*}{ Stage 1} & Schedule 1 & 200 & - & - & - & - & 324 & 95 & 19 \\
\hline & Schedule 2 & 12 & - & - & - & - & 308 & 95 & 19 \\
\hline & Schedule 3 & 1 & - & - & - & - & & 88 & 19 \\
\hline \multirow{3}{*}{ Stage 2} & Schedule 4 & 12 & 3.13 & 1150 & - & - & 363 & 91 & 15 \\
\hline & Schedule 5 & 12 & 3.13 & 1050 & - & - & 443 & 92 & 3.5 \\
\hline & Schedule 6 & 12 & 3.13 & 900 & - & - & 464 & & - \\
\hline \multirow{3}{*}{ Stage 3} & Schedule 7 & 100 & 3.13 & 1050 & 600 & - & 434 & 0 & - \\
\hline & Schedule 8 & 100 & 3.13 & 1050 & 600 & 1000 & 800 & 30 & - \\
\hline & Schedule 9 & 100 & 3.13 & 1050 & 600 & 1000 & 840 & - & - \\
\hline *Legend & \multicolumn{9}{|c|}{$\begin{array}{c}\text { DT - deformation temperature, TT - tempering temperature, RHT - reheating } \\
\text { austenitizing temperature, } \mathrm{H} \text { - hardness, AF - austenite fraction, GS - austenite grain } \\
\text { size }\end{array}$} \\
\hline
\end{tabular}

\section{DISCUSSION OF RESULTS}

Stage 1: effects of the rate of cooling from the semi-solid region on the character of the network and the austenite morphology

At the first stage of the experiment, the primary focus was on exploring the effects of the rate of crossing the solidus curve during cooling. In schedule 1, very rapid cooling at $200 \mathrm{~K} / \mathrm{s}$ was used, which led to a microstructure consisting of austenite grains embedded in ledeburite (Fig.1a). This microstructure is characteristic of semi-solid processing with rapid solidification. The austenite volume fraction found by X-ray diffraction was $95 \%$. The structure resulting from air cooling from the soaking temperature of $1265^{\circ} \mathrm{C}$ (schedule 2) was similar in terms of morphology. It consisted, too, of austenite grains embedded in ledeburitic network. However, the lamellae making up this network were notably coarser than in the previous case (Fig.1b). The austenite grain size was identical in both variants: $19 \mu \mathrm{m}$. The cooling rate influenced the appearance of grain boundaries which became jagged and intertwined with the network. In both cases, the austenite volume fraction was identical: $95 \%$. The coarser nature of the ledeburitic network was reflected in the lower hardness. While schedule 1 led to the level of $324 \mathrm{HV} 30$; the hardness upon schedule 2 was 308 HV30. 

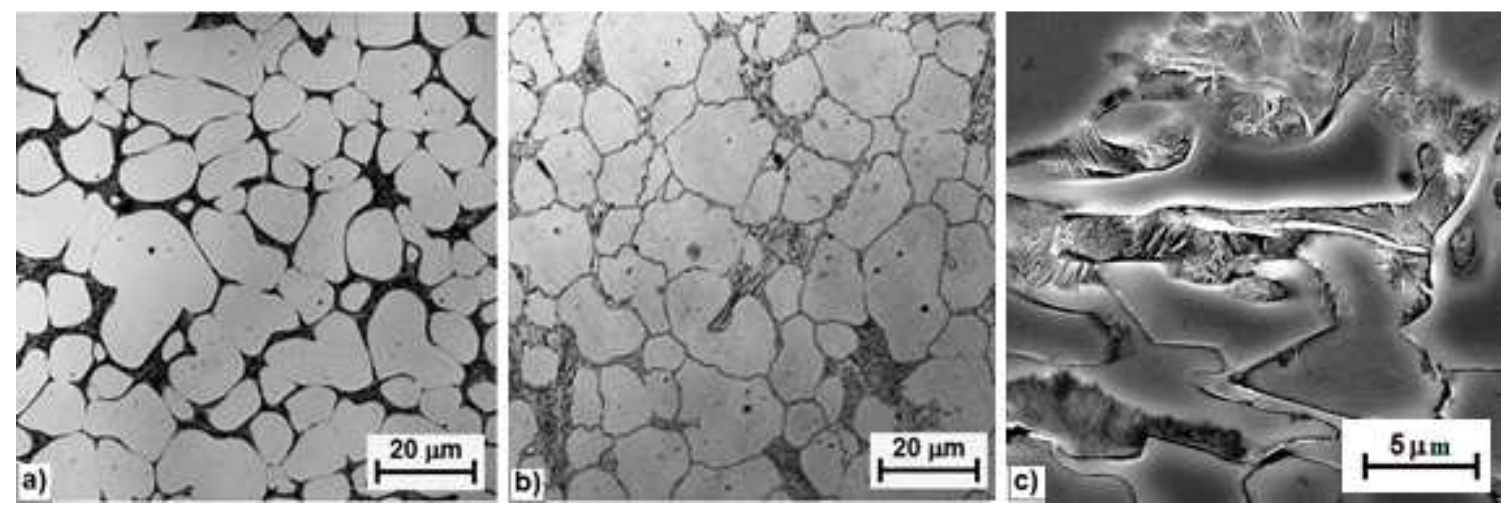

Fig. 1 Microstructures upon transition through semi-solid state: a) on quenching (schedule 1), b) on air cooling (schedule 2), c) detail of the microstructure after the onset of austenite decomposition (schedule3)

Controlled cooling at $1 \mathrm{~K} / \mathrm{s}$ used in schedule 3 supported coarsening of the carbide network. Very slow cooling also initiated austenite decomposition. At the grain boundaries, austenite decomposed into very fine troostite. The detail scanning electron micrograph confirmed the start of austenite decomposition not only along primary austenite grain boundaries but also within austenite grains embedded in the ledeburitic network (Fig.1c). The size of these nuclei did not exceed $10 \mu \mathrm{m}$. As a result, no substantial decrease in the amount of austenite was detected, as the level found was $88 \%$.

Stage 2: Effect of deformation below the solidus line on the microstructure

At the second stage of the experiment, the effects of deformation upon cooling below the solidus line were explored. In schedule 4, the deformation applied at $1150{ }^{\circ} \mathrm{C}$, which is $72{ }^{\circ} \mathrm{C}$ below the solidus line, caused a profound change in the character of the microstructure. No polyhedral austenite grains were retained within the network. The carbide-austenite network was converted into clusters between disintegrated austenite grains (Fig. 2a). The austenite content remained virtually unchanged: $95 \%$. The change in the morphology of the microstructure and the distribution of phases led to a slightly higher hardness of $363 \mathrm{HV} 30$. Image analysis was used to determine the mean austenite grain size: $15 \mu \mathrm{m}$, which is $4 \mu \mathrm{m}$ less than upon deformation-free schedules.

Schedule 5 involved a lower deformation temperature, $1050{ }^{\circ} \mathrm{C}$, than the previous procedure. Austenite grains were substantially recrystallized and their mean size was $3 \mu \mathrm{m}$ (Fig. 2b). The carbide areas were distributed more uniformly within the microstructure. The appearance shows that the material was deformed in a completely solid condition. Deformation led to extensive recrystallization, grain refinement and disintegration of the carbide network and to a more uniform distribution of carbides within the microstructure. The hardness level rose to 443 HV 30.
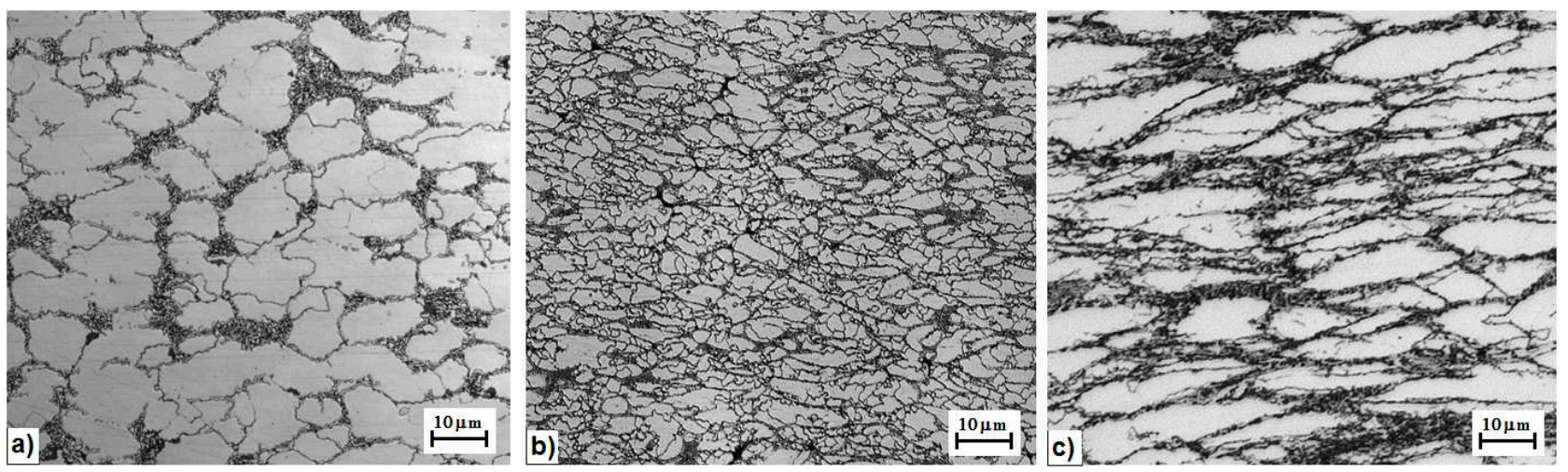

Fig. 2 Effects of various deformation temperatures on microstructure evolution: a) deformation at $1150{ }^{\circ} \mathrm{C}$ (schedule 4), b) deformation at $1050{ }^{\circ} \mathrm{C}$ (schedule 5), a) deformation at $900{ }^{\circ} \mathrm{C}$ (schedule 6) 
A further reduction in the deformation temperature $\left(900^{\circ} \mathrm{C}\right)$ in schedule 6 led to a notable alignment and elongation of grains as a result of deformation (Fig. 3c). Work hardening of the material led to an increase in hardness to the level of $464 \mathrm{HV} 30$. The austenite grain size was not measured, as their elongated nature would distort the outcome.

Stage 3: Effect of isothermal holding or heat treating on austenite decomposition

At the third stage, the first experiment involved holding at $600{ }^{\circ} \mathrm{C}$ between cooling from the soaking temperature as part of schedule 7 . This isothermal hold was preceded by deformation at $1050^{\circ} \mathrm{C}$. The resulting microstructure consisted of fine pearlite with dispersed chromium carbides (Fig. 3). The length of pearlite lamellae was on the order of several micrometers, and their thickness was approximately $100 \mathrm{~nm}$. The microstructure still contained primary chromium carbides along prior grain boundaries. The hardness was 434 HV30. No retained austenite was detected by X-ray diffraction. Schedule 8 involved cooling to the ambient temperature followed by reheating to the austenite region and air cooling. The resulting microstructure was completely different from the conventional ones. The reheating above $\mathrm{Ac}_{3}$ re-austenitized the material. The subsequent cooling induced partial decomposition of austenite into martensite and chromium carbides (Fig. 4). However, $30 \%$ retained austenite remained in the microstructure. In this case, remnants of chromium carbides were detected along prior austenite grain boundaries as well. The hardness of the material processed in this manner was approx. $800 \mathrm{HV} \mathrm{30.} \mathrm{This} \mathrm{substantial} \mathrm{increase} \mathrm{in} \mathrm{hardness,}$ which is greater than that in the other schedules, is due to formation of martensite during cooling from austenitizing temperature.
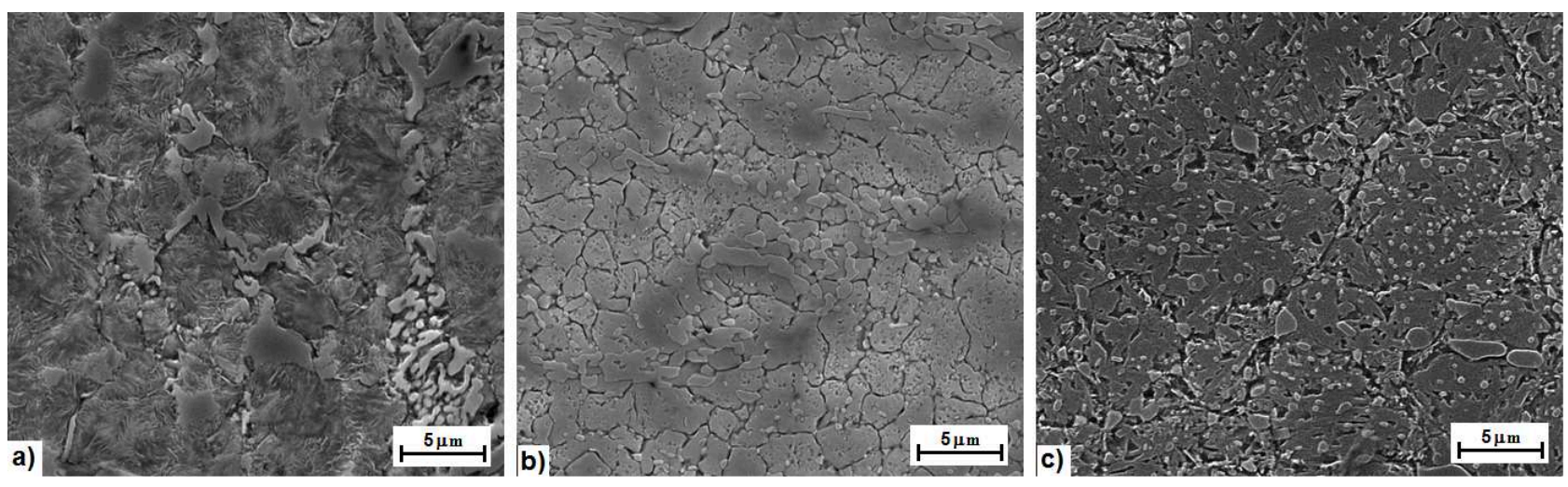

Fig. 3 Microstructure after tempering: a) schedule 7, b) schedule 8, c) schedule 9,

The last schedule, no. 9 , involved heating to $1000^{\circ} \mathrm{C}$. The subsequent cooling was interrupted by holding at $500{ }^{\circ} \mathrm{C}$, the purpose of which was to induce decomposition of the remaining austenite. The hold caused the retained austenite to decompose into fine martensite needles and uniformly dispersed globular carbide precipitates. These processes brought an increase in hardness to $846 \mathrm{HV} 30$.

\section{Summary}

The present experiment was aimed at describing the effects of the cooling rate, deformation in the solid state and subsequent heat treating upon the evolution of microstructure in the X210Cr12 tool steel. It was found that while the solidification rate has a profound impact on the fineness of the carbide network, it has no effect on the austenite volume fraction or the size of austenite grains. Reducing the cooling rate to a mere $1 \mathrm{~K} / \mathrm{s}$ causes the austenite decomposition to set in and leads to considerable coarsening of the primary chromium carbides. Deformation after cooling to the solid state initiates the expected dynamic recrystallization which is otherwise uncommon upon semi-solid processing. The last stage of the experiment showed that the subsequent heat treatment can lead to an unconventional martensite-austenite microstructure with a hardness of 800 HV30. Tempering 
causes its retained austenite to decompose into martensite and leads to precipitation of fine carbides and the resulting increase in hardness to $840 \mathrm{HV} 30$.

\section{Acknowledgement}

The authors gratefully acknowledge funding by the German Research Foundation (Deutsche Forschungsgemeinschaft, DFG) and the Czech Science Foundation (Grantová agentura České republiky, GAČR) through the joint, binational projects WA 2602/2-1 and GA ČR P107/11/J083.

\section{References}

[1] W. Püttgen, W. Bleck, G. Hirt, H Shimahara: Advanced Engineering Materials 9, No. 4 (2007), pp. 231-245.

[2] I. Sen, H. Jirkova, B. Masek, M. Böhme, M.F.-X. Wagner, Microstructure and mechanical behavior of a mini-thixoformed tool steel, Metall. Mater. Trans. A, 43 (2012), 3034-3038.

[3] H. Jirkova,et al., Mini-thixoforming of a steel produced by powder metallurgy, Solid State Phenom., 192-193 (2013),pp 500-505.

[4] P. Cezard, R. Bigot, V. Favier and M. Robelet, Advanced Methods in Material Forming (2007), pp 309-320

[5] D.I. Uhlenhaut, J. Kradolfer, W. Puttgen, J.F. Loffler, P.J. Uggowitzer, Acta Materialia 54 (2006), pp. 2727-2734

[6] W. Püttgen, B. Hallstedt, W. Bleck, P. J. Uggowitzer, Acta Materialia 55 (2007) 1033-1042.

[7] JMatPro, The Java-based Materials Property Simulation Package, Version 6.1, Sente Software Ltd., Surrey Technology Center, UK

[8] Mašek et. al, Journal of Alloys and Compounds, Vol 504 (2010), pp500 - 503 